\title{
Perbandingan Keanekaragaman Spesies dan Kelimpahan Arthropoda Predator Penghuni Tanah di Sawah Lebak yang Diaplikasi dan Tanpa Aplikasi Insektisida
}

\author{
SITI HERLINDA ${ }^{1)}$, WALUYO ${ }^{2)}$, S. P. ESTUNINGSIH ${ }^{3)}$, CHANDRA IRSAN ${ }^{1)}$ \\ ${ }^{1}$ Jurusan Hama dan Penyakit Tumbuhan, Faperta, Universitas Sriwijaya \\ ${ }^{2}$ Program Studi Pengelolaan Lingkungan Program Pascasarjana, Universitas Sriwijaya \\ ${ }^{3}$ Jurusan Biologi FMIPA, Universitas Sriwijaya
}

(diterima Mei 2008, disetujui Agustus 2008)

\begin{abstract}
Species Diversity and Abundance Comparison of the Soil-dwelling predatory-arthropods Inhabiting Fields Applied by Insecticide and without Insecticide Application. Studies on soil-dwelling predatory arthropods were carried out in lowland areas of South Sumatra, with objectives to analyze the species diversity and abundance of the predatoryarthropods inhabiting fields applied by synthetic insecticide, bioinsecticide, and without insecticide application. The predatory arthropods were sampled using pitfall traps. Indices of diversity and community similarities were applied to analyze the data. Results indicated that the arthropods inhabiting field without insecticide application had the highest diversity and abundance compared to other treatments. Predatory community similarities between those on the field without insecticide application and applied by bioinsecticide were higher compared to the fields applied by synthetic insecticide.
\end{abstract}

KEY WORDS: diversity, abundance, predatory arthropod

\section{PENDAHULUAN}

Budidaya tanaman padi sawah lebak di Sumatera Selatan memiliki ciri khas, yaitu masih rendahnya input yang dilakukan oleh petani di ekosistem tersebut. Umumnya petani menanam padi tanpa melakukan penyemprotan pestisida dan pemupukan dilakukan seperlunya, namun satu hal yang paling menarik bahwa pada ekosistem padi rawa lebak ini belum pernah terjadi peledakan populasi hama. Sebaliknya di Jalur Pantai Utara Jawa Barat (Pantura), yang input pestisidanya tinggi, sering muncul peledakan populasi hama seperti laporan Settle et al. (1996). Peledakan populasi hama ini menunjukkan ketidakberdayaan musuh alaminya (Settle et al. 1996; Wiedenmann \& Smith 1997; Wissinger 1997). Gangguan hama merupakan "penyakit ekologis" yang mencerminkan kerapuhan suatu ekosistem karena adanya pengenceran peran musuh alami akibat penggunaan 
insektisida atau pestisida sintetik yang kurang bijaksana.

Di ekosistem persawahan, arthropoda predator (serangga dan laba-laba) merupakan musuh alami yang paling berperan dalam menekan populasi hama padi (wereng coklat dan penggerek batang) (Thalib et al. 2002). Hal ini disebabkan predator memiliki kemampuan untuk beradaptasi di ekosistem efemeral tersebut (Wiedenmann \& Smith 1997; Herlinda \& Effendy 2003; Herlinda et al. 2004). Arthropoda predator yang telah terbukti efektif mengendalikan hama padi adalah laba-laba pemburu, misalnya Pardosa pseudoannulata (Kromp \& Steinberger 1992; Settle et al. 1996) dan kumbang Carabidae (Kromp \& Steinberger 1992).

Winasa dan Rauf

melaporkan terjadinya penurunan kelimpahan Arthropoda permukaan tanah dari famili Lycosidae, Lyniphiidae, Carabidae dan Formicidae pada ekosistem sawah yang diaplikasi deltametrin. Penurunan serangga fitofag dan Arthropoda predator juga terjadi pada ekosistem sawah yang diaplikasi profenofos dan deltametrin (Purwanta et al. 1997). Penelitian tentang keanekaragaman dan kelimpahan Arthropoda predator di ekosistem sawah yang diaplikasi dan tanpa aplikasi insektisida sintetik di Sumatera Selatan belum dilakukan. Penelitian ini bertujuan untuk menganalisis keanekaragaman spesies dan kelimpahan Arthropoda predator yang menghuni permukaan tanah di sawah yang diaplikasi insektisida sintetik, bioinsektisida, dan tanpa aplikasi insektisida.

\section{BAHAN DAN METODE}

Penelitian ini dilakukan pada bulan Juli sampai November 2007. Luas sawah untuk petak contoh tanpa aplikasi insektisida dan aplikasi bioinsektisida masing-masing satu hektar terletak di Desa Gandus, Kota Palembang, sedangkan untuk aplikasi insektisida sintetik terletak di Desa Sungai Dua, Kabupaten Banyuasin seluas satu hektar yang berjarak sekitar $20 \mathrm{~km}$. Insektisida sintetik yang digunakan tersebut berbahan aktif fipronil $50 \mathrm{~g} / \mathrm{l}$, yaitu insektisida sistemik dengan cara kerja racun kontak. Aplikasi bioinsektisida dilakukan pada saat padi berumur 14 hst (hari setelah tanam), 25 hst, 39 hst, 53 hst, dan 67 hst. Bioinsektisida yang digunakan berbahan aktif Beauveria bassiana (Bals.) Vuill. yang cara pembuatannya mengikuti metode Herlinda et al. (2008). Sawah tempat penelitian termasuk tipe lebak tengahan. Varietas padi yang ditanam pada areal penelitian adalah IR 64 .

\section{Pengambilan Contoh Arthropoda Predator}

Pengambilan Arthropoda pada permukaan tanah menggunakan lubang jebakan (pitfall trap) seperti metode Price dan Shepard (1980), Whitcomb 
(1980), Niemele et al. (1990), dan McEwen (1997). Lubang jebakan terbuat dari gelas plastik berdiameter $50 \mathrm{~mm}$ dan kedalaman $100 \mathrm{~mm}$. Perangkap tersebut lalu diisi larutan formalin 4\% sebanyak satu pertiga tinggi gelas.

Lubang jebakan dipasang di permukaan tanah dan diusahakan permukaannya rata dengan permukaan tanah di sekitarnya, lalu ditutup dengan pelepah pisang yang dipasang tiang setinggi $15 \mathrm{~cm}$ dari permukaan tanah. Jumlah lubang jebakan yang dipasang berjumlah 36 buah (total 3 ulangan) pada setiap lokasi per pengamatan. Posisi perangkap tersebar merata di lokasi pengamatan. Perangkap di pasang di pematang sawah dengan jarak antar perangkap sekitar $15 \mathrm{~m}$. Pemasangan perangkap berlangsung saat padi berumur 4 minggu setelah tanam (mst), $6 \mathrm{mst}, 8 \mathrm{mst}, 10 \mathrm{mst}$ dan 1 minggu setelah panen (msp). Penyemprotan pada petak yang diaplikasi insektisida sintetik dilakukan pada saat padi berumur 14 hst, 25 hst, 39 hst, 53 hst, dan 67 hst.

Arthropoda yang terperangkap dalam lubang jebakan disaring dengan saringan teh dan dibersihkan sambil dibilas dengan air mengalir. Selanjutnya, dimasukkan ke dalam tabung film berisi alkohol 70\% untuk diidentifikasi di laboratorium. Identifikasi Artropoda didasarkan pada ciri morfologinya. Identifikasi Arthropoda dilakukan di Laboratorium Entomologi, Jurusan
Hama Penyakit Tumbuhan, Fakultas Pertanian, Universitas Sriwijaya. Identifikasi arthropoda menggunakan acuan buku deGunst (1957), Kalshoven (1981), Lawrence dan Britton (1984), Hadlington dan Jhonston (1987), Barrion dan Litsinger (1990), Hilsenhoff (1991), Shepard et al. (1991), dan Barrion dan Litsinger (1994).

\section{Analisis Data}

Data komposisi spesies dan jumlah individu Arthropoda predator digunakan untuk menganalisis kelimpahan dan keanekaragaman spesies Arthropoda predator. Ukuran keanekaragaman yang dipergunakan ialah nilai indeks keanekaragaman spesies Shannon, indeks dominasi spesies Berger-Parker dan indeks kemerataan spesies dari Pielou menggunakan buku Magurran (1988). Untuk membandingkan kemiripan komunitas Arthropoda predator antar perlakuan digunakan indeks Sorensen menggunakan buku Ludwig dan Reynolds (1988).

\section{HASIL DAN PEMBAHASAN}

\section{Kelimpahan dan Keanekaragaman Spesies Artropoda Predator}

Jumlah Arthropoda yang aktif di permukaan tanah pada sawah tanpa aplikasi insektisida dan diaplikasi bioinsektisida lebih tinggi disebandingkan dengan sawah yang diaplikasi insektisida sintetik (Tabel 1). Jumlah Arthropoda pada sawah yang 
Tabel 1. Jumlah famili, spesies dan kelimpahan relatif artropoda yang aktif pada permukaan tanah

\begin{tabular}{|c|c|c|c|c|c|c|c|c|c|}
\hline \multirow{2}{*}{ Kelas, Ordo, Famili } & \multicolumn{3}{|c|}{ Tanpa aplikasi insektisida } & \multicolumn{3}{|c|}{ Aplikasi insektisida } & \multicolumn{3}{|c|}{ Aplikasi bioinsektisida } \\
\hline & JS & JI & KR & JS & JI & $\mathrm{KR}$ & JS & JI & $\mathrm{KR}$ \\
\hline \multicolumn{10}{|l|}{ Kelas Insecta } \\
\hline \multicolumn{10}{|l|}{ Ordo Coleoptera } \\
\hline Carabidae (Pr) & 10 & 735 & 29,36 & 8 & 193 & 26,01 & 10 & 544 & 29,55 \\
\hline Cucujidae (Pg) & 1 & 97 & 3,88 & 1 & 13 & 1,75 & 1 & 63 & 3,42 \\
\hline Elateridae (Pg) & 1 & 31 & 1,24 & 1 & 9 & 1,21 & 1 & 28 & 1,52 \\
\hline Longuriidae (Pg) & 1 & 32 & 1,28 & 1 & 38 & 5,12 & 1 & 29 & 1,58 \\
\hline Nitiduiidae (Pg) & 1 & 60 & 2,40 & 1 & 35 & 4,72 & 1 & 47 & 2,55 \\
\hline Phoeostichidae (Pg) & 1 & 50 & 2,00 & 1 & 26 & 3,50 & 1 & 38 & 2,06 \\
\hline Korynetidae (Pg) & 1 & 103 & 4,12 & 1 & 51 & 6,87 & 1 & 75 & 4,07 \\
\hline Staphylinidae (Pr) & 1 & 44 & 1,76 & 1 & 14 & 1,89 & 2 & 32 & 1,74 \\
\hline Attelabidae (Pg) & 0 & 0 & 0,00 & 1 & 1 & 0,13 & 0 & 0 & 0,00 \\
\hline Scarabidae (Fit, Pg) & 0 & 0 & 0,00 & 0 & 0 & 0,00 & 1 & 2 & 0,11 \\
\hline Anthicidae $(\mathrm{Pg})$ & 1 & 1 & 0,04 & 1 & 1 & 0,13 & 0 & 0 & 0,00 \\
\hline Cureulionidae (Pg) & 1 & 1 & 0,04 & 0 & 0 & 0,00 & 0 & 0 & 0,00 \\
\hline Catantopidae (Pg) & 1 & 3 & 0,12 & 0 & 0 & 0,00 & 0 & 0 & 0,00 \\
\hline Hybosoridae (Pg) & 0 & 0 & 0,00 & 1 & 1 & 0,13 & 0 & 0 & 0,00 \\
\hline \multicolumn{10}{|l|}{ Ordo Hymenoptera } \\
\hline Formicidae (Pr) & 6 & 566 & 22,61 & 6 & 200 & 26,95 & 5 & 484 & 26,29 \\
\hline \multicolumn{10}{|l|}{ Ordo Ortoptera } \\
\hline Gryllotalpidae (Fit) & 1 & 9 & 0,36 & 0 & 0 & 0,00 & 1 & 9 & 0,49 \\
\hline Gryllidae (Pr, Fit) & 4 & 60 & 2,40 & 3 & 13 & 1,75 & 5 & 59 & 3,20 \\
\hline Blatidae (Pg) & 0 & 0 & 0,00 & 0 & 0 & 0,00 & 1 & 1 & 0,05 \\
\hline Acrididae (Fit) & 3 & 38 & 1,52 & 1 & 5 & 0,67 & 3 & 51 & 2,77 \\
\hline Pyrogomorphidae (Pg) & 1 & 27 & 1,08 & 0 & 0 & 0,00 & 1 & 12 & 0,65 \\
\hline \multicolumn{10}{|l|}{ Ordo Hemiptera } \\
\hline Coreidae (Fit) & 1 & 1 & 0,04 & 0 & 0 & 0,00 & 0 & 0 & 0,00 \\
\hline \multicolumn{10}{|l|}{ Ordo Dermaptera } \\
\hline Forficulidae (Pr) & 0 & 0 & 0,00 & 1 & 1 & 0,13 & 0 & 0 & 0,00 \\
\hline \multicolumn{10}{|l|}{ Kelas Arachnida } \\
\hline Lycosidae (Pr) & 4 & 447 & 17,86 & 4 & 93 & 12,53 & 4 & 254 & 13,80 \\
\hline Tetragnatidae (Pr) & 4 & 15 & 0,60 & 3 & 3 & 0,40 & 4 & 7 & 0,38 \\
\hline Oxyopidae (Pr) & 2 & 11 & 0,44 & 2 & 4 & 0,54 & 1 & 6 & 0,33 \\
\hline Salticidae (Pr) & 2 & 43 & 1,72 & 2 & 5 & 0,67 & 2 & 6 & 0,33 \\
\hline Linyphiidae (Pr) & 2 & 65 & 2,60 & 1 & 22 & 2,96 & 1 & 46 & 2,50 \\
\hline Araneidae $(\mathrm{Pr})$ & 1 & 64 & 2,56 & 2 & 14 & 1,89 & 1 & 48 & 2,61 \\
\hline Total & 51 & 2503 & 100 & 43 & 742 & 100 & 48 & 1841 & 100 \\
\hline
\end{tabular}

diaplikasi insektisida sintetik lebih rendah dibandingkan dengan sawah yang diaplikasi bioinsektisida dan lebih rendah dibandingkan dengan sawah tanpa aplikasi insektisida.

Arthropoda yang aktif pada permukaan tanah yang kelimpahannya 
tertinggi ialah famili Carabidae, Formicidae, dan Lycosidae. Terdapat 28 famili lain yang aktif di permukaan tanah namun kelimpahannya relatif rendah. Rendahnya kelimpahan populasi Arthropoda pada ekosistem sawah yang diaplikasi insektisida sintetik tersebut menunjukkan bahwa insektisida sintetik dapat mempengaruhi kelimpahan populasi arthropoda yang aktif di permukaan tanah. Penurunan populasi arthropoda permukaan tanah pada sawah yang diaplikasi insektisida sintetik diduga akibat dari kerentanan arthropoda itu terhadap insektisida sintetik

Populasi laba-laba Lycosidae pada sawah yang diaplikasi insektisida sintetik sangat rendah, diduga hal itu dipengaruhi oleh tubuhnya yang lunak dan peka terhadap insektisida sintetik serta cara hidupnya yang aktif di permukaan tanah menyebabkan arthropoda tersebut mudah terpapar insektisida sintetik (Winasa \& Rauf 2005).

Kelimpahan relatif kumbang Carabidae pada sawah tanpa aplikasi insektisida sintetik relatif sama dengan sawah yang diaplikasi bioinsektisida. Artinya bioinsektisida sintetik tidak mempengaruhi kelimpahan kumbang Carabidae. Kelimpahan relatif famili Formicidae pada sawah yang diaplikasi insektisida sintetik hampir sama dengan sawah yang diaplikasi bioinsektisida bahkan relatif lebih tinggi dibandingkan dengan sawah tanpa aplikasi insektisida. Diduga hal itu erat kaitannya dengan ketahanan spesies serangga yang tergolong ke dalam famili Formicidae. Samways (1995) menyatakan Formicidae salah satu spesies serangga yang relatif tahan terhadap insektisida. Secara umum insektisida sintetik berpengaruh terhadap kelimpahan arthropoda. Penelitian sebelumnya yang dilakukan oleh Winasa \& Rauf (2005) menunjukkan bahwa kelimpahan kumbang Carabidae, Formicidae dan laba-laba Lycosidae di lahan yang diaplikasi insektisida sintetik relatif rendah.

Keanekaragaman spesies serangga yang aktif di permukaan tanah pada sawah tanpa aplikasi insektisida lebih tinggi dibandingkan dengan keanekaragaman spesies serangga pada sawah yang diaplikasi insektisida sintetik maupun bioinsektisida. Pada sawah tanpa aplikasi insektisida ditemukan 36 spesies serangga dan 15 spesies laba-laba, pada sawah yang diaplikasi bioinsektisida ditemukan 35 spesies serangga dan 13 spesies laba-laba, dan pada sawah yang diaplikasi insektisida sintetik ditemukan 29 spesies serangga dan 14 spesies laba-laba. 

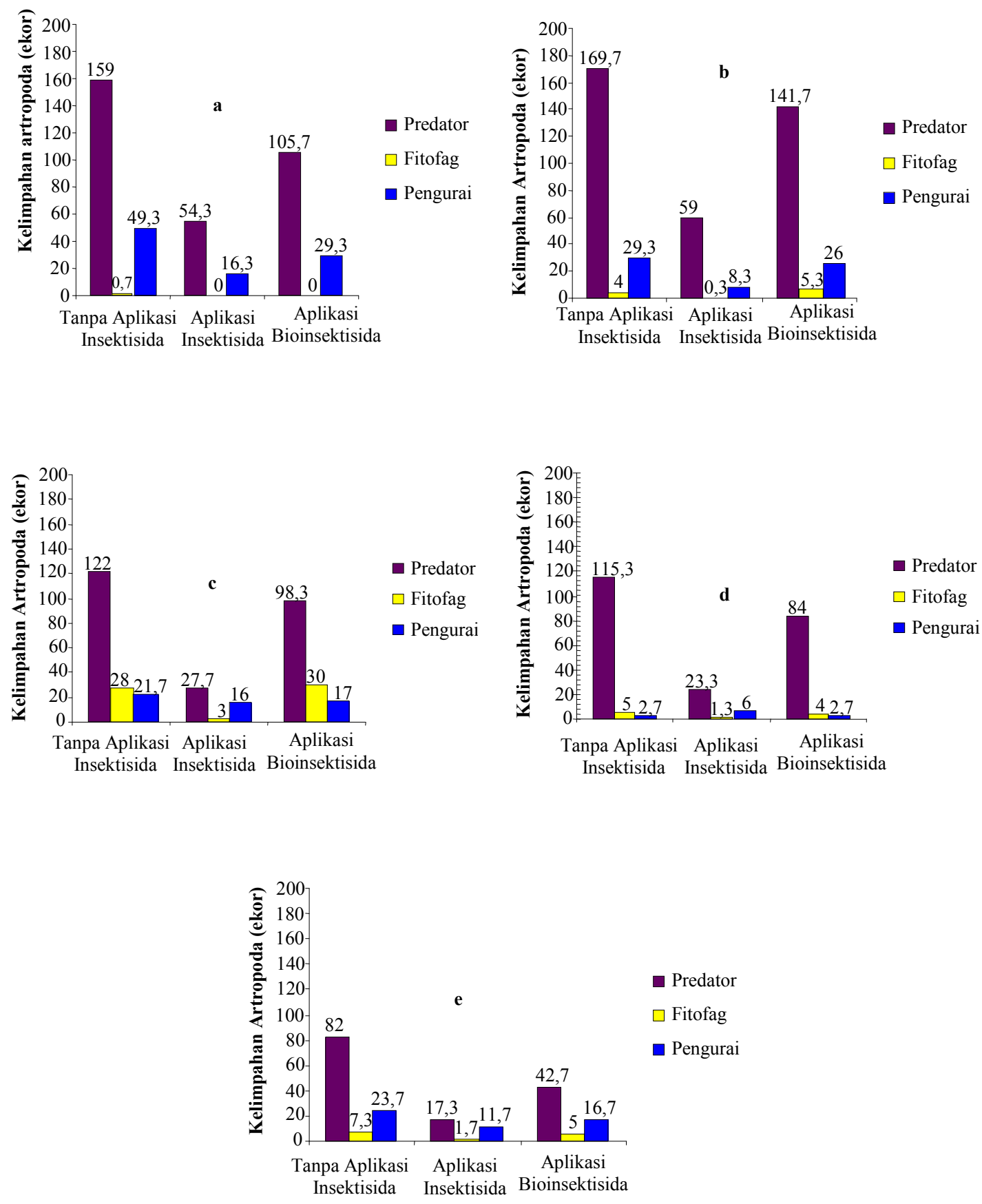

Gambar 1. Kelimpahan Arthropoda yang aktif di permukaan tanah berdasarkan tingkat tropik pada padi umur 4 mst (a), 6 mst (b), 8 mst (c), 10 mst (d) dan $1 \mathrm{msp}(\mathrm{e})$

Hal itu menunjukkan bahwa insektisida sintetik berpengaruh terhadap keanekaragaman spesies serangga yang aktif di permukaan tanah di sawah. Keanekaragaman spesies Arthropoda 
yang aktif di permukaan tanah di sawah terdapat pada Tabel 1.

Kelimpahan Arthropoda yang aktif di permukaan tanah berdasarkan tingkat tropik (Gambar 1) yang ditemukan pada sawah tanpa aplikasi insektisida menunjukkan bahwa pada umur padi $4 \mathrm{mst}$ serangga predator, fitofag dan pengurai lebih tinggi dibandingkan pada sawah yang diaplikasi insektisida sintetik. Pada umur $6 \mathrm{mst}$, serangga predator dan serangga pengurai pada sawah tanpa sawah yang diaplikasi insektisida dibandingkan dengan sawah tanpa aplikasi insektisida dan yang diaplikasi bioinsektisida, kondisi ini bertahan sampai padi berumur $8 \mathrm{mst}$. Hal ini disebabkan turunnya kelimpahan Arthropoda predator sebagai pemangsa serangga fitofag akibat dari pengaruh insektisida sintetik yang menyebabkan serangga predator banyak yang mati sehingga jumlah serangga fitofag meningkat. Selain itu, banyaknya serangga fitofag karena pada $6 \mathrm{mst}$ dan $8 \mathrm{mst}$ adalah masa perkembangan vegetatif padi sehingga serangga fitofag jumlahnya melimpah karena pada masa tersebut banyak serangga fitofag mencari makan. Pada umur $10 \mathrm{mst}$ serangga predator dan fitofag pada sawah tanpa aplikasi insektisida lebih tinggi dibandingkan sawah yang diaplikasi insektisida sintetik, sedangkan serangga pengurai pada sawah tanpa aplikasi insektisida lebih rendah bila dibandingkan sawah yang diaplikasi insektisida sintetik.

Pada umur 1 msp baik serangga predator, fitofag, dan pengurai pada sawah tanpa aplikasi insektisida jumlahnya lebih tinggi dibandingkan sawah yang diaplikasi insektisida sintetik. Ini berhubungan dengan tidak adanya lagi tajuk padi sehingga kemungkinan hilangnya serangga yang dimangsa, sehingga menyebabkan serangga tersebut pergi mencari tempat lain yang masih menyediakan mangsa.

Walaupun terjadi peningkatan serangga fitofag dan serangga pengurai pada setiap masa umur padi, tetapi selalu diikuti oleh peningkatan jumlah serangga predator sehingga serangga fitofag tetap terkendali jumlahnya. Peningkatan kerapatan populasi juga dilaporkan oleh Widiarta et al. (2006) pada budidaya secara organik yang tidak menggunakan bahan sintetik sama sekali dalam pengolahan lahan pertanaman padi. Purwanta et al. (1997) melaporkan terjadinya peningkatan serangga fitofag pada sawah yang diaplikasi insektisida sintetik. Jumlah keseluruhan predator permukaan tanah pada sawah tanpa diaplikasi insektisida dan sawah yang diaplikasi bioinsektisida lebih tinggi dibandingkan dengan sawah yang diaplikasi insektisida sintetik (Tabel 2). Hal ini menunjukkan bahwa insektisida sintetik berpengaruh buruk terhadap kehidupan predator penghuni permukaan tanah. Kelompok predator 
yang kelimpahannya menurun adalah kelompok kumbang Carabidae, Staphilinidae, Formicidae, laba-laba Lycosidae, Salticidae, Linyphiidae, dan Araneidae.

\section{Karakteristik Komunitas Arthropoda Predator}

Indeks keanekaragaman Arthropoda yang aktif di permukaan tanah tertinggi adalah sawah tanpa aplikasi insektisida, kemudian diikuti oleh sawah yang diaplikasi bioinsektisida dan yang terendah adalah sawah yang diaplikasi insektisida sintetik. Indeks keanekaragaman artropoda yang aktif pada permukaan tanah terdapat pada Tabel 3.

Tingginya indeks keanekaragaman spesies Arthropoda yang aktif pad permukaan tanah di sawah tanpa aplikasi insektisida karena di sawah tersebut tidak terpapar bahan kimia insektisida yang dapat menurunkan jumlah individu dalam populasi di sawah tersebut. Menurut Widiarta et al. (2006), akibat dari terpaparnya insektisida di areal persawahan dapat menurunkan keanekaragaman spesies serangga.

Tabel 2. Kelimpahan Arthropoda predator penting yang aktif di permukaan tanah di sawah

\begin{tabular}{lccc}
\hline \hline & \multicolumn{2}{c}{ Kelimpahan Arthropoda predator (ekor) } \\
\cline { 2 - 4 } Kelas dan Famili & $\begin{array}{c}\text { Tanpa aplikasi } \\
\text { insektisida }\end{array}$ & $\begin{array}{c}\text { Aplikasi } \\
\text { insektisida }\end{array}$ & $\begin{array}{c}\text { Aplikasi } \\
\text { bioinsektisida }\end{array}$ \\
\hline Insekta & 254 & 64,33 & 186,67 \\
Carabidae & 14,67 & 4,67 & 10,33 \\
Staphylinidae & 188,67 & 66,67 & 161,33 \\
Formicidae & 149 & 31 & 81,67 \\
Arachnida & 14,33 & 1,67 & 3,00 \\
Lycosidae & 21,67 & 7,33 & 15,33 \\
Salticidae & 21,33 & 4,67 & 16,00 \\
Linyphiidae & 654,67 & 180,34 & 474,33 \\
Araneidae & & & \\
\hline Total & & & \\
\hline
\end{tabular}

Tabel 3. Karakteristik komunitas Arthropoda yang aktif pada permukaan tanah di sawah

\begin{tabular}{lccc}
\hline Karakteristik komunitas & $\begin{array}{c}\text { Tanpa aplikasi } \\
\text { insektisida }\end{array}$ & $\begin{array}{c}\text { Aplikasi } \\
\text { insektisida }\end{array}$ & $\begin{array}{c}\text { Aplikasi } \\
\text { bioinsektisida }\end{array}$ \\
\hline Kelimpahan (ekor) & 2503 & 742 & 1833 \\
Jumlah spesies & 51 & 41 & 49 \\
Indeks Shannon & 3,20 & 3,07 & 3,05 \\
Indeks Berger-Parker & 0,14 & 0,14 & 0,15 \\
Indeks Pielou & 0,92 & 0,83 & 0,78 \\
\hline
\end{tabular}


Hal yang sama juga dilaporkan oleh Purwanta et al. (1997) dan Winasa \& Rauf (2005). Jadi tingginya indeks keanekaragaman spesies serangga di sawah tanpa aplikasi insektisida karena di areal tersebut tidak pernah menggunakan bahan kimia dalam mengendalikan serangga yang mengganggu tanaman. Namun, di sawah yang diaplikasi insektisida sintetik indeks keanekaragaman spesiesnya rendah. Hal ini disebabkan karena pada sawah tersebut terpapar bahan kimia yang dapat menyebabkan menurunnya sebaran jumlah individu dalam spesies. Dengan demikian, penurunan sebaran individu dapat mengakibatkan terjadinya penurunan nilai indeks keanekaragaman spesies serangga di areal tersebut.

Indeks dominasi Arthropoda yang aktif di permukaan tanah tertinggi pada sawah yang diaplikasi bioinsektisida, Pada sawah, tanpa aplikasi insektisida dan sawah yang diaplikasi insektisida sintetik mempunyai nilai yang sama (Tabel 3). Kemerataan spesies artropoda yang aktif di permukaan tanah tertinggi pada sawah tanpa aplikasi insektisida. Kemudian diikuti sawah yang diaplikasi insektisida sintetik dan yang terendah pada sawah yang diaplikasi bioinsektisida.

Tingginya tingkat dominasi Arthropoda yang aktif pada permukaan tanah pada sawah yang diaplikasi insektisida sintetik menunjukkan adanya ketidakseimbangan populasi antar spesies serangga. Tingginya tingkat dominasi di suatu ekosistem berarti terjadi dominasi yang sangat tinggi oleh spesies tertentu dibandingkan dengan spesies yang lain. Pada sawah yang diaplikasi insektisida sintetik tingkat kemerataan spesiesnya lebih rendah dibandingkan dengan sawah tanpa aplikasi insektisida. Tingginya tingkat dominasi dan rendahnya tingkat kemerataan spesies serangga pada ekosistem yang diaplikasi insektisida sintetik juga dilaporkan oleh Purwanta et al. (1997) dan Widiarta et al. (2006).

\section{Kemiripan Komunitas}

Komunitas Arthropoda yang aktif di permukaan tanah pada sawah tanpa aplikasi insektisida lebih mirip dengan sawah yang diaplikasi bioinsektisida dibandingkan dengan sawah yang diaplikasi insektisida sintetik (Tabel 4). Kemiripan komunitas Arthropoda pada sawah tanpa aplikasi insektisida dan yang diaplikasi bioinsektisida lebih tinggi bila dibandingkan dengan komunitas Arthropoda pada sawah yang diaplikasi insektisida sintetik karena bioinsektisida relatif lebih aman untuk kehidupan serangga bila dibandingkan insektisida sintetik. Akibatnya pengaruh bioinsektisida mirip dengan pengaruh tanpa aplikasi insektisida. 
Tabel 4. Matriks kemiripan spesies (indeks Sorensen) Arthropopda yang aktif pada permukaan tanah di sawah

\begin{tabular}{lccc}
\hline \hline \multirow{2}{*}{ Tipe ekosistem } & \multicolumn{3}{c}{ Tipe ekosistem } \\
\cline { 2 - 4 } & $\begin{array}{c}\text { Tanpa aplikasi } \\
\text { insektisida }\end{array}$ & $\begin{array}{c}\text { Aplikasi } \\
\text { insektisida } \\
\text { sintetik }\end{array}$ & $\begin{array}{c}\text { Aplikasi } \\
\text { bioinsektisida }\end{array}$ \\
\hline Tanpa aplikasi insektisida & 1,00 & 1,00 & \\
Aplikasi insektisida & 0,87 & 0,82 & 1,00 \\
Aplikasi bioinsektisida & 0,88 & 0,00 \\
\hline
\end{tabular}

Penggunaan bahan kimia dalam pengolahan lahan pertanian dapat menyebabkan terpaparnya bahan tersebut di lingkungan, maka kemungkinan ada spesies Arthropoda tertentu yang mati atau meninggalkan tempat tersebut. Hal ini dapat berakibat pada kelimpahan dan keanekaragaman Arthropoda di sawah yang diaplikasi insektisida sintetik menjadi rendah, Rendahnya kelimpahan dan keanekaragaman spesies Arthropoda di ekosistem dapat menyebabkan rendahnya tingkat kemiripan komunitas antar habitat.

Agus (2007) melaporkan ekosistem alami memiliki keanekaragaman yang tinggi dibandingkan ekosistem pertanian. Sawah tanpa aplikasi insektisida dan sawah yang diaplikasi bioinsektisida tidak menggunakan bahan kimia sintetik dalam pengolahan lahan pertanian, maka sawah tersebut lebih mirip ekosistem alami dibandingkan sawah yang diaplikasi insektisida sintetik. Akibatnya, tingkat kemiripan komunitas pada sawah tanpa aplikasi insektisida dan sawah yang diaplikasi bioinsektisida lebih tinggi dibandingkan sawah yang diaplikasi insektisida sintetik. Tingginya tingkat kemiripan arthropoda dilaporkan juga oleh Herlinda (2000) antara pematang sawah dan tepi saluran irigasi yang kedua habitat tersebut tidak diaplikasi insektisida sintetik dengan pertanaman padi yang memiliki tipe yang lebih mirip dibanding dengan Arthropoda semak dan pertanaman padi.

\section{KESIMPULAN}

Aplikasi insektisida sintetik mempengaruhi keanekaragaman dan kelimpahan Arthropoda predator yang aktif di permukaan tanah. Komunitas Artropoda predator pada sawah tanpa aplikasi insektisida sintetik kemiripannya lebih tinggi dengan yang diaplikasi bioinsektisida bila dibandingkan komunitas yang diaplikasi insektisida sintetik. Keanekaragaman dan kelimpahan Arthropoda yang aktif di permukaan tanah tertinggi ditemukan pada sawah tanpa diaplikasi insektisida yang terdiri dari 51 spesies (2503 individu) dan terendah pada sawah yang diaplikasi insektisida sintetik yang terdiri dari 43 spesies (742 individu). 


\section{UCAPAN TERIMA KASIH}

Penelitian ini merupakan bagian dari Insentif Riset Terapan yang didanai oleh Program Insentif, Kementerian Negara Riset dan Teknologi, sesuai dengan Surat Perjanjian Pelaksanaan Program Insentif Tahun Anggaran 2007 Nomor: 94/RT/Insentif/PPK/I/2007, tanggal 15 Januari 2007 a.n. Siti Herlinda.

\section{DAFTAR PUSTAKA}

Agus YH. 2007. Keanekaragaman Collembola, Semut dan LabaLaba Permukaan Tanah. [Disertasi], Bogor: Program Pascasarjana, IPB.

Barrion AT, Litsinger JA. 1994. Taxonomy of Rice Insect Pest and Their Arthropod Parasites and Predators, In Heinrichs EA (ed), Biology and Management of Rice Insect, Wiley Easterm Limited, New Delhi p,13-362.

Barrion AT, Litsinger JA. 1990, Taxonomy of Rice Insect Pest and Their Arthropod Parasites and Predator. International Rice Research Institute, Philippines, $580 \mathrm{p}$.

deGunst JH. 1957. Indonesia lady-bird, Penggemar Alam, 36:3-17.

Hadlington PW, Johnston JA. 1987. An Introduction to Australia Insects. South China Printing Co, Hongkong, 116p,

Herlinda S. 2000. Analisis Komunitas Artropoda Predator Penghuni Lansekap Persawahan di Daerah Cianjur. Jawa Barat, [Disertasi], Bogor: Program Pascasarjana, IPB.
Herlinda S, Effendy TA. 2003. Jenis Artropoda predator penghuni tajuk dan permukaan tanah di ekosistem tanaman padi, M23,1-7. Prosiding Seminar Lokakarya Nasional Ketahanan Pangan dalam Era Otonomi Daerah dan Globalisasi, Palembang 2-4 Maret 2003.

Herlinda S, Mulyati SI, Suwandi. 2008. Jamur entomopatogen untuk mengendalikan wereng coklat pada tanaman padi, Agritrop 27(3):119-126.

Herlinda S, Rauf A, Sosromarsono S, Kartosuwondo U, Siswadi, Hidayat P. 2004. Artropoda musuh alami penghuni ekosistem persawahan di daerah Cianjur, Jawa Barat. J, Entomol, Ind, 1:915.

Hilsenhoff WL. 1991. Diversity and classification of insect and collembolan, p, 593-664, In J,H, Thorp \& Covich AP (eds). Ecology and Classification of North America Freshwater Invertebrates. Academic Press, Inc, San Diego.

Kalshoven LGE. 1981. Pest of Crops in Indonesia. Revised and Translated by van der Laan, PT, Ichtiar Baru -van Hoeven, Jakarta, 701p.

Kromp B, KH Steinberger. 1992. Grassy field margins and arthropod diversity: a case study on ground beetles and spiders in Eastern Austria (Coleoptera: Carabidae; Arachnidae: Aranei, Opiliones). Agric. Ecosyst. Environ 40:71-93,

Lawrence JF, Britton EB. 1994. Australian Beetle. Melbourne University Press, Victoria, 192p. 
Ludwig JA, Reynolds JF. 1988. Statistical Ecology: A Primer on Methods and Computing. John Wiley \& Sons, New York, 337p.

Magguran AE. 1988. Ecological Diversity and Its Measurement, Princeton University Press, New Jersey, 179p.

McEwen P. 1997. Sampling, handling and rearing insect, $p, 5-26$, In Dent DR \& Walton MP(eds) Methods in Ecological \& Agricultural Entomology, University Press, Cambridge.

Niemela JN, Halme E, Haila Y. 1990.Balancing sampling effort in pitfall trapping of carabid beetles, Entomol, Fennica, 1:233-238.

Price JF, Shepard M. 1980. Sampling ground predators in soybean fields, p, 530-543, In, Kogan M\& Herzog DC(eds,), Sampling Methods in Soybean Entomology, Springer-Verlag, New York.

Purwanta FX, Rauf A, Kartosuwondo U, Sastrosiswoyo W 1997. Pengaruh aplikasi insektisida terhadap komunitas artropoda pada agroekosistem kedelai, Makalah disampaikan pada Seminar Nasional PHT, Subang, 16-19 Juni 1997.

Samway MJ. 1995. Insect Conservation Biology, Chapman \& Hall, London, 358p.

Settle WH, Ariawan H, Astuti ET, Cahyana W, Hakim AL, Hindayana D, Lestari AS, Pajarningsih. 1996. Managing tropical rice pest through conservation of generalist natural enemies and alternative prey. Ecology, 77:1975-1988.
Shepard BM, Barrion AT, Litsinger JA. 1991. Friends of the Rice Farmer: Helpful Insects, Spiders and Phatogens, International Rice Research Institut, Philippines, $136 \mathrm{p}$.

Thalib R, Effendy TA, Herlinda S. 2002. Struktur komunitas dan potensi artropoda predator hama padi penghuni ekosistem sawah dataran tinggi di daerah Lahat, Sumatera Selatan, Makalah Seminar Nasional Dies Natalis Fakultas Pertanian Universitas Sriwijaya \& Peringatan Hari Pangan Sedunia, Palembang, 7-8 Oktober 2002.

Whitcomb WH. 1980. Sampling spiders in soybean fields, $p, 544-$ 558, In, M Kogan, Herzog DC (eds,), Sampling Methods in Soybean Entomology, SpringerVerlag, New York.

Widiarta IN, Kusdiaman, Suprihanto. 2006. Keragaman artropoda pada padi sawah dengan pengelolaan tanam terpadu, JHPTT 6:61-69

Wiedenmann RN, Smith JW. 1997. Attributes of natural enemies in ephemeral crop habitat, Biol, Contr, 10:16-22.

Winasa IW, Rauf A. 2005. Pengaruh sampling aplikasi deltametrin terhadap artropoda predator penghuni permukaan tanah di pertanaman kedelai. J, Entomol. Ind. 2:39-47.

Wissinger SA. 1997. Cyclic colonization in predictably ephemeral habitat habitat: A template for biological control in annual crop systems. Biol. Contr. 10:4-15. 